\title{
Entretelones y alcances del tratado de libre comercio
}

\author{
Alberto Acosta*
}

$\int$

a ampliación de los mercados para sus productos

y sus inversiones es una de las prioridades de los la única. Con esta propuesta EE.UU. quiere asegurar su posición hegemónica en el hemisferio en vista del fortalecimiento y expansión de la Unión Europea (UE). Recuérdese que el ALCA, propuesto a fines de 1994, también fue una respuesta al Mercado Común del Cono Sur (MERCOSUR), en tanto propuesta de integración subregional que no se ajusta a la lógica de apertura comercial y financiera asimétrica impulsada por Washington. Y, por cierto, en esta nueva iniciativa estadounidense no están ausentes las razones geopolíticas y militares, sobre todo desde el 11 de septiembre del 2001. El Plan Colombia y el Plan Puebla Panamá deben, por tanto, integrarse en el análisis del ALCA y del Tratado de Libre Comercio.

Como reconoce públicamente Robert B. Zoellick, quien fuera representante comercial de EE.UU. en el primer período presidencial de George Bush II, en carta del 18 de noviembre de 2003, dirigida a J. Dennis Hastert, presidente de la Cámara de Representantes de EE.UU. "Un TLC con los países andinos ayudaría a promover la integración económica entre los cuatro países que conforman la Comuni-

* Miembro del Instituto Latinoamericano de Investigaciones Sociales (ILDISFES), asesor de varias organizaciones ciudadanas, indígenas y sindicales y docente universitario. 
dad Andina de Naciones. Al mismo tiempo, brindaría oportunidades de exportación para los proveedores de productos agrícolas, industriales y de servicios de Estados Unidos. Serviría como un complemento natural al Plan Colombia, al que el Congreso ha dado un apoyo significativo a lo largo de los años".

Frente a esta realidad, los defensores del llamado "libre comercio" olvidan, desconocen o esconden que la historia y la realidad desmitifican la existencia de libertad en el comercio. Y, por supuesto, tampoco están interesados en descubrir las amenazas que el "libre comercio" implica, en cualquiera de sus presentaciones: ALCA o TLC.

\section{Una vieja aspiración de los EE.UU.}

Una vez más, Estados Unidos busca la unión económica de todo el continente americano, aspiración formulada ya en la Primera Conferencia Internacional Americana a fines del siglo XIX, en Washington. En este nuevo intento, plasmado en la propuesta del Área de Libre Comercio de las Américas (ALCA), presentada por Bill Clinton (1994), que se nutre de la denominada Iniciativa de las Américas planteada en 1990 por George Bush I y que incluso se intenta plasmar por la vía de tratados bilaterales, los EE.UU. tienen varios objetivos.

Marco Romero nos recuerda, que "los Estados Unidos manifestaron su interés por mantener una relación privilegiada, obviamente desde su perspectiva y de sus intereses, con los países situados al Sur del río Bravo, desde comienzos del siglo XIX. El nacimiento de naciones independientes de la corona española y del imperio portugués contó con el apoyo limitado de los norteamericanos (al igual que de algunas potencias europeas, principalmente de 
Gran Bretaña y Alemania), más que por fortalecer una tendencia independentista, en la región por restringir los privilegios de que gozaban esas potencias europeas, para crear oportunidades de disputar espacios para su propia expansión, así como para abrir nuevos mercados para sus manufacturas y capitales que manifestaban tendencias a desbordar sus fronteras, todavía en pleno movimiento, hasta comienzos del siglo XX".

"La formulación más clara de la visión norteamericana sobre la región y especialmente sobre sus relaciones con los países latinoamericanos y de El Caribe estará dada por la Doctrina Monroe, formulada en diciembre de 1823; ella surgía de la preocupación por la presencia y especialmente por las periódicas intenciones de las potencias europeas, de ocupar o mantener posiciones en el continente americano. Ella planteaba su oposición a cualquier avance de potencias extranjeras; definiendo que "América era para los americanos", se oponía a cualquier nueva colonización europea en la región".

"Por supuesto que las capacidades económicas, políticas y militares que tenían entonces los Estados Unidos no lo convertían en un rival de peso para la potencia británica. En la práctica esa doctrina se aplicaría solo en forma parcial y casuística, a lo largo del siglo diecinueve, dependiendo de los intereses norteamericanos en presencia, de los conflictos de poder en Europa y de los arreglos directos que se establecían entre los Estados Unidos y las potencias europeas involucradas. Debido a esta preocupación por el rol de Europa en la región, los Estados Unidos se vieron involucrados en los conflictos internacionales en el hemisferio. El objetivo norteamericano "era impedir que se restaurase el antiguo orden colonial de mercantilismo económico y autoritarismo político"; para evitarlo preveía crear un "sistema americano" que no se basara únicamente en los prin- 
cipios económicos liberales, sino también en las libertades civil, política y religiosa".

"Durante medio siglo eso pudo hacerse sin usar abiertamente la fuerza, pero ya bajo la concepción del "destino manifiesto" por la cual los Estados Unidos se atribuían una misión histórica y daban un alcance continental a su visión de la expansión continental, que mezclaba elementos económicos, políticos, estratégicos, culturales y religiosos. Sería a comienzos del siguiente siglo, bajo la administración de Theodore Roosevelt, que se consolidaría la afirmación del poder policial de los Estados Unidos, principalmente en el Caribe, "como una consecuencia natural de la doctrina Monroe", imponiéndose "una doctrina de intervención preventiva", conocida como el "corolario Roosevelt de la doctrina Monroe".

Como contrapartida, siguiendo a Romero, recordemos que "la visión estadounidense de América y de su rol en el mundo contrasta claramente con la planteada por Simón Bolívar a la salida de las luchas independentistas; él fue quien inspiró en 1822 la formación de una liga de naciones entre Colombia, Perú y Centroamérica y en 1826 propició el Congreso Interamericano de Panamá, también fueron invitados Estados Unidos e Inglaterra (como observadora). Básicamente buscaba promover la cooperación y el desarrollo político entre las nuevas naciones.

Posteriormente, ya en el siglo XX, las relaciones de EE.UU. con sus vecinos del sur estuvo influenciada por las grandes confrontaciones bélicas de alcance mundial. Con el ALCA, los EEUU replantearán su política con los países latinoamericanos y caribeños. Relación que está también signada por razones bélicas, sintetizadas en la lucha en contra del narcotráfico; aquí se destacan particularmente, el Plan Colombia y la Iniciativa Regional Andina, las ATPDEA. 


\section{La realidad del "libre comercio"}

Para empezar, a escala internacional, y salvo algunas excepciones nacionales, nunca hubo una real libertad económica. Ni siquiera Gran Bretaña, para recordar a la primera nación capitalista industrializada con vocación global, practicó la libertad comercial; con su flota impuso, en varios rincones del planeta, sus intereses: introdujo a cañonazos el opio a los chinos, a cuenta de la presunta libertad de comercio o bloqueó los mercados de sus extensas colonias para protegerlos con el fin de mantener el monopolio para colocar sus textiles, por ejemplo. Los alemanes, inspirados en Friedrich List (1789-1846), lograron su desarrollo con medidas proteccionistas en contra del discurso librecambista dominante en el siglo XIX. Los estadounidenses buscaron una senda diferente a la que predicaban los ingleses; Ulysses Grant, héroe de la guerra de secesión y luego presidente de EE.UU. (1868-1876), fue categórico cuando declaró que "dentro de 200 años, cuando América haya obtenido del proteccionismo todo lo que pueda ofrecer, también adoptará el libre comercio"; y vaya que lo lograron antes, incluso apoyándose una y otra vez en sus marines. Y los países asiáticos, Japón y ahora China inclusive, tampoco fueron ni son librecambistas.

Lo cierto es que una vez que los países ricos obtuvieron sus objetivos, han reclamado de los otros la adopción del libre comercio, la desregulación de las economías, la apertura de los mercados de bienes y de capitales, la adopción de instituciones adecuadas a la racionalidad empresarial, a su cultura empresarial transnacional, se entiende. Así, hoy, más allá del discurso dominante, no hay todavía tal libre mercado. Y si bien las recetas del neoliberalismo realmente existente han fracasado en términos de generar bienestar a la mayoría de la población, no lo han hecho en 
su búsqueda de una nueva división internacional del trabajo globalizada en función de las demandas del capital transnacional.

Vista desde la experiencia histórica y de la realidad presente, la intención de los gobiernos andinos de Colombia, Ecuador y Perú, para firmar bilateralmente convenios de "libre comercio" con EE.UU., debido a que el programa de preferencias arancelarias andinas expira en diciembre de 2006, solo es entendible por la ignorancia reinante o por la complicidad con los intereses internacionales supeditados a las recomendaciones de política económica neoliberales sintetizadas en el denominado "Consenso de Washington» que, con pocas variantes, se avalizaron en las "cartas de intención» y en los acuerdos suscritos entre los diferentes gobiernos y el Fondo Monetario Internacional (FMI), así como con el Banco Mundial a través de sus Estrategias de Asistencia al País (CAS, por sus siglas en inglés). De todas formas, el punto de partida de cualquier análisis serio pasa por reconocer el interés de quien propone el ALCA/TLC: Ios EE.UU., y por definir, con claridad, las reglas que exige el mercado mundial tal como es.

El hecho de que no haya existido, ni exista un mercado mundial libre no quiere decir que su establecimiento vaya a asegurar los objetivos planteados por sus panegíricos.

Hay que tener presente que en la actualidad, a escala planetaria, existe todo un marco de regulaciones y prácticas que norman el comercio mundial, elaborado por y para los países más poderosos. Más allá del discurso de la libertad de los mercados, el mercado mundial se caracteriza por ser un espacio administrado. Las declaraciones de los gobiernos de los países ricos, orientadas a beneficiar a los países empobrecidos del Sur, se contradicen con la realidad, en la medida en que con sus políticas comerciales marginan las exportaciones de los países pobres. Téngase presente, que 190 
las diversas barreras al comercio cuestan a los países subdesarrollados sumas enormes, superiores a toda la llamada ayuda al desarrollo.

\section{Una América Latina ajustada, un terreno abonado para el "libre comercio"}

Sin perder de vista la complejidad de la política global desplegada por Estados Unidos y, por cierto, las cambiantes condiciones vinculadas a la globalización del sistema capitalista, hay que reconocer que desde hace más de dos décadas se han aplicado políticas de ajuste estructural en América Latina, con diversos grados de intensidad y coherencia. Esta región, sobre todo desde los años ochenta, y más aún en los noventa en el siglo XX ha estado fuertemente condicionada por las profundas reformas económicas aplicadas en el marco de los programas de ajuste estructural del Fondo Monetario Internacional (FMI) y del Banco Mundial, que postularon entre sus metas principales la apertura comercial, la liberalización financiera y la reforma minimizadora del Estado, incluyendo la privatización de empresas públicas y la creciente protección a las inversiones extranjeras.

Al hacer un balance de la aplicación de estas políticas, se puede indicar que las crisis económicas recurrentes han afectado a México, Brasil, Argentina, Turquía, Indonesia, Corea, Malasia, Filipinas, Tailandia y Ecuador. También Bolivia, que en la década de los ochenta incurrió en un draconiano programa de ajuste ideado por el pensamiento dominante y que se le presentaba como el nuevo modelo neoliberal, ha caído nuevamente en una profunda crisis social y política. Incluso destacados personajes del stablishment han advertido sobre la persistente iniquidad en la distribución del ingreso a nivel global (Stiglitz, 2002). 
Atrás quedaron los años en los que se intentó una inserción en el mercado mundial a partir del desarrollo de las capacidades locales: la estrategia de industrialización vía sustitución de importaciones. Las economías de la región están cada vez más abiertas. Su comercio exterior creció en forma acelerada. Su sed de capitales foráneos aumentó también en forma progresiva. Como consecuencia de tanta apertura y liberalización, las influencias externas son cada vez más notorias en la región y sus países han perdido aceleradamente espacios de soberanía en términos de políticas económicas. Y esta pérdida de capacidad para accionar y reaccionar frente a los vaivenes en el mercado mundial, que -vale la pena insistir- se refleja en una inserción pasiva y hasta ingenua en el mercado mundial, ha abonado el terreno para el ALCA/TLC. Así, en el campo del comercio, vía apertura comercial, el espíritu del ALCA/TLC es una realidad aún antes de que se suscriba dicho acuerdo. En el campo de la protección de las inversiones extranjeras, las propuestas del ALCA pueden ser apreciadas a plenitud en el Tratado de Libre Comercio de América del Norte (TLCAN, o NAFTA en su sigla en inglés: North American Free Trade Agreement), tema que se abordará más adelante.

En este espíritu se inscribe el ALCA (e incluso la negociación bilateral de los Tratados de Libre Comercio) que, en suma, es una suerte de apuesta de última instancia para poner en vigencia la totalidad del Washington Consensus (WC).

Hay que reconocer, por otro lado, que el "libre comercio" encontró el terreno propicio para su formulación en unas economías desgastadas en sus bases nacionales como resultado del ajuste estructural ya mencionado, al que se llegó como consecuencia de las sucesivas negociaciones de la deuda externa y sus consiguientes condiciona- 
mientos. Y es en este contexto que se debe comprender el alcance de las reformas inspiradas en el WC. En el campo comercial, ello ha significado una desgravación arancelaria de carácter unilateral, aplicada con diferente intensidad en cada uno de los países de la región. Los países latinoamericanos abrieron sus fronteras a las importaciones, en el marco de los condicionamientos fondomonetaristas. América Latina se colocó a la vanguardia de la liberalización comercial, mientras los países desarrollados, con EE.UU. a la cabeza, recurrían a todo tipo de barreras para controlar las importaciones provenientes de los países subdesarrollados. Como se ha visto una y otra vez, las sucesivas reformas introducidas en la Ley de Comercio de EE.UU. han reforzado el neoproteccionismo norteamericano, consolidando la posición de sus productos en el exterior también mediante negociaciones comerciales bilaterales, regionales y multilaterales.

Los EE.UU., en especial, han aplicado en las últimas décadas una política comercial que combina el proteccionismo en los sectores en los que ha perdido competitividad, con la promoción del libre comercio para sus productos, en particular en los sectores en que son competitivos, en el resto del mundo. Washington ha recurrido también al uso de las restricciones "voluntarias" a las exportaciones; a la acusación de dumping, definido por su gobierno de manera arbitraria; a la imposición de cuotas; y a una variedad de instrumentos legales proteccionistas, como lo es el Tratado de Preferencias Arancelarias Andinas y Erradicación de la Droga (ATPDEA, por su siglas en inglés), para "premiar" la sumisión de los gobiernos andinos a la política norteamericana de combate al narcotráfico o para castigar a los países que tomen medidas que puedan afectar las inversiones norteamericanas. El uso y abuso de estas leyes implica beneficios para unos y perjuicios para otros, en función de los intereses estadounidenses. 
Este neoproteccionismo, sustentado sobre todo en medidas no arancelarias, en muchos casos rebasa el efecto de los anteriores aranceles. Y tampoco faltan salvaguardias arancelarias como las aplicadas en el año 2002 al acero por parte del régimen de George Bush II. Incluso el TLC es una propuesta proteccionista para favorecer los intereses del aparato productivo estadounidense.

De lo anterior se desprende que el repetido abuso del poder de Washington margina la vigencia del tan promocionado (y, por cierto, inexistente) "libre" mercado. Por otro lado, la "libertad" resulta apenas la muletilla del más fuerte, tanto como la "igualdad de derechos", ambas elementos de un discurso y no de una práctica. E incluso en el caso de que se avanzase en una senda de libertad e igualdad, esta, al ser intentada a partir de desequilibrios enormes, solo beneficiará al más poderoso; en este caso, a EE.UU.

EI ALCA/TLC, para que no quepa la más mínima duda, sintetiza la pretensión de Washington para ampliar a todo el hemisferio la vigencia del TLCAN, cuyo peso es determinante en esta integración mercantilista, pero no oculta los objetivos políticos imperiales. Como reconoce Susanne Gratius, en un interesante análisis realizado desde una perspectiva europea, "el ALCA es preminentemente una iniciativa de EE.UU. para mantener su competitividad económica e influencia política en el mundo". Lo que dicho en palabras de Colin Powel, Secretario de Estado, significa que "nuestro objetivo con el ALCA es garantizar para las empresas norteamericanas, el control del territorio que va desde el polo Ártico hasta la Antártida y el libre acceso sin ningún obstáculo o dificultad, a nuestros productos, servicios, tecnología y capital en todo el hemisferio". 


\section{Los riesgos de una novelería}

Para empezar, como ha sucedido otras veces, dentro de la lógica del ALCA/TLC está cerrada la puerta para la búsqueda de una alternativa real. No hay la más mínima posibilidad para que, en las actuales circunstancias, instancias oficiales y de la gran empresa asuman las demandas y potencialidades nacionales como punto de partida para definir una concepción estratégica que permita construir una base soberana para participar con inteligencia y creatividad en el contexto internacional, negociando incluso con los EE.UU., el principal mercado de las exportaciones andinas y uno de sus principales abastecedores. Tampoco hay mucho espacio para aprovechar el potencial provocado por el reciente acercamiento entre el MERCOSUR y la Comunidad Andina de Naciones (CAN), que constituiría una instancia más adecuada para negociar con la primera potencia del mundo.

Peor que eso, en la práctica no hay una real negociación con los EE.UU. Tal como sucede en los otros países andinos, el equipo "ecuatoriano" -financiado y aleccionado por instancias multilaterales pro apertura y liberalizaciónseguirá defendiendo los intereses del librecambismo o sea los intereses del WC, presentes desde hace tiempo atrás. Esto es clave para entender lo que sucede y para no pecar de ingenuos asumiendo que recién con el TLC se rifarán las economías andinas y latinoamericanas. Estas ya han sido bastante rifadas en la ruleta del neoliberalismo. Por eso, sea con el TLC o con el ALCA, o simplemente por la vía de las Cartas de Intención, se seguirá imponiendo la lógica del "libre comercio".

$Y$ bien sabemos que con las reformas planteadas para instrumentalizar el "libre comercio" se asegura: 
- La apertura comercial de las economías de la región, sin que los EE.UU. estén dispuestos a revisar sus esquemas proteccionistas, los subsidios a la agricultura, por ejemplo.

- La potestad para que solo las empresas con capital norteamericano puedan demandar a los gobiernos fuera de las legislaciones nacionales: el arbitraje.

- La limitación para que los estados de la región puedan desarrollar políticas industriales proactivas, al prohibírseles que impongan cuotas mínimas de exportación, grados o porcentajes mínimos de contenido nacional, preferencias por bienes producidos o servicios prestados en su territorio, relacionar el valor o el volumen de las importaciones con el volumen o valor de exportaciones, reglas de transferencia de tecnologías o conocimientos.

- La prohibición de los controles sobre el movimiento de capitales: se reduce aún más la capacidad de acción de los estados frente las empresas transnacionales.

- La posibilidad para que todos los servicios -educación, salud, pensiones, jubilaciones, vivienda, seguridad, agua- puedan ser privatizados, esto es, puedan pasar a manos de inversionistas norteamericanos.

- La eliminación de restricciones que impidan a las empresas privadas monopolizar patentes, incluso de aquellas que afecten los conocimientos comunitarios de los pueblos indígenas.

- El establecimiento de normas que dejen abiertas exclusivamente a mecanismos de mercado a las compras de gobierno; esto limita la capacidad para que el gobierno central o los gobiernos seccionales puedan influir positivamente con medidas que favorezcan a los productores locales.

- La pretendida libre movilidad del capital y de las mercancías, sin flexibilizar la política migratoria restrictiva de Estados Unidos. 
En síntesis, los derechos de las personas jurídicas y sus propietarios tienen más jerarquía que los derechos de los seres humanos y de los estados-nación de la América latina y caribeña. El ALCA o los TLC, en definitiva, se inscriben en la lógica exacerbada del sistema capitalista, que encuentra en Washington, en términos amplios, uno de sus principales centros de expansión transnacional.

$Y$ lo que interesa es el alcance de las reformas inspiradas en el WC, que resultan en extremo preocupantes. El ALCA/TLC tendrá categoría supraconstitucional: los compromisos que se asuman serán (casi) imposibles de revertir. El destino de los países de la región quedará marcado por mucho tiempo. El ALCA/TLC, ya lo dijimos, no es solo un acuerdo comercial, tampoco se reduce a los temas mencionados anteriormente. Este abarca temas que afectarán "la soberanía y la defensa nacional, la autonomía en el diseño y aplicación de políticas estatales, la potestad legislativa del Congreso, la jurisdicción de nuestras leyes y tribunales, nuestros derechos y deberes ciudadanos", como atinadamente afirmó el legislador peruano Javier Diez Canseco (2004); en suma, afectarán el destino de los países de la región por décadas.

En este contexto, el "libre comercio" en el campo socioeconómico, con sus correspondientes implicaciones políticas, consolidará una modalidad de acumulación primario exportadora, sustentada en diversas formas de "competitividad espuria", particularmente en la sobreexplotación de los recursos naturales y de la mano de obra, antes que en el espíritu emprendedor y creativo del empresariado. Esto a su vez ahondará la dependencia de una demanda externa volátil, con los consiguientes impactos en las cuentas externas e incluso mantendrá o aun aumentará el endeudamiento externo. $Y$ este tipo de integración internacional conduce a la desintegración nacional, tal como se mencionó antes. 
En estas circunstancias, se diluirán aún más las posibilidades para un desarrollo nacional sustentable y equitativo.

Aquí también es urgente anticipar los problemas que se ciernen en la región por la competencia desatada entre los países que ingenua y hasta torpemente pretenden suscribir a como de lugar un acuerdo con los EE.UU. El "libre comercio" provoca conflictos de diversa índole entre los países del Sur, en tanto cada país, envuelto en un conflicto fratricida, intenta disputar a costa de sus vecinos y a dentelladas un mercado que no es infinito. Este enfrentamiento, que también se registra en el ámbito financiero para atraer inversión extranjera sacrificando cada vez más las opciones para impulsar el desarrollo, se agudiza en la actualidad por efecto de la competencia desatada en medio de las diversas negociaciones bilaterales en marcha.

Por eso, como punto de partida, cualquier negociación con una potencia global como los EE.UU. se debería partir por comprender todos los riesgos existentes. En este punto urgen análisis serios sobre las amenazas que implica el "libre comercio". Para eso ya hay suficiente material para el estudio al cabo de una década de TLC en México y por cierto también en la reciente negociación del TLC con Chile o con los mismos países centroamericanos. Solo conociendo estas realidades y las potencialidades nacionales se podrá formular una alternativa para oponerse a que se cristalice -sin discusión alguna y en forma autoritaria- la peligrosa necedad del TLC.

\section{La vieja práctica de quitar la escalera}

Sin preocuparse por la verdad, los seguidores del "libre comercio" afirman que ese fue el camino seguido por los países exitosos. Cuando, en realidad esos países no fueron cultores del librecambio y menos aún del recetario fondomonetarista. 
Una y otra vez recurrieron y recurren al proteccionismo o a mecanismos arbitrarios que limitan o alientan en su beneficio los flujos comerciales y últimamente los flujos de servicios y de capitales. Y en la práctica no están dispuestos a permitir que otros países alcancen su nivel de bienestar. Ya lo reconocía el alemán Friedrich List, cuando en 1841 analizaba la situación de la economía inglesa, "es una norma corriente de prudencia, una vez que se ha alcanzado la cima de la grandeza (gracias al desarrollo industrial, $\mathrm{NdA}$ ), quitar la escalera por la que se ha trepado para evitar que otros puedan subir detrás de nosotros. Aquí está el secreto de las teorías cosmopolitas de Adam Smith (...).

Una nación que con medidas protectoras (...) consigue un grado tan elevado de desarrollo para su fuerza manufacturera (...), hasta el punto de no temer la competencia de ninguna otra, no puede hacer nada más prudente que retirar esta escalera de su grandeza y predicar a las demás naciones las ventajas de la libertad de comercio".

Y esto de "quitar la escalera" se refleja con claridad en el tema agrícola. Aquí, por ejemplo, las trabas al comercio, que no serán removidas con el ALCA/TLC, pues Washington no quiere negociar con sus vecinos del Sur el tema de los subsidios a la agricultura, son la norma. El subsidio a los agricultores representó entre 1998-2000 el 63\% de la renta agraria en el Japón, el $40 \%$ en la Unión Europea, $23 \%$ en los EE.UU. y $18 \%$ en Canadá, según OXFAM. El subsidio por agricultor en los EE.UU., en el 2000, significó 20.803 dólares al año y en la Unión Europea 16.028 dólares (en total unos mil millones de dólares diarios), mientras que el ingreso promedio en los países de renta intermedia fue de 2.000 dólares y en los países de renta baja alcanzó apenas 410 dólares; países en los que la agricultura es la principal o al menos una de las más importantes actividades económicas. 
Por otro lado, debe quedar constancia de los riesgos que implica la apertura planteada por Washington para la agricultura, para la naturaleza y para la vida misma de los pueblos de latinoamericanos y caribeños. Keynes (1933) comprendió hace décadas este peligro, puesto que "los procesos agrícolas tienen raíces profundas, ellos mismos encuentran soluciones lentamente, son resistentes al cambio y desobedecen a un orden administrativo, y a pesar de ello son delicados y frágiles, cuando han sufrido daños, no se recuperan con facilidad".

A pesar de que en la OMC cada país tiene un voto, a diferencia del FMI o del Banco Mundial, en la práctica esta es -como denuncia Eduardo Gudynas- "una institución antidemocrática donde la enorme mayoría de los países en desarrollo son marginados en el proceso de elaborar propuestas, arrinconándolos a la hora de las votaciones finales para aceptar los acuerdos tomados por las naciones industrializadas con un grupo de gobiernos del Sur." Además, para prevenir reclamos desmedidos, el poder global ha corrido el mensaje de que si los pobres "piden demasiado", se quedarán sin nada; riesgo mínimo si se recuerda que muchos representantes del Sur son enceguecidos defensores de las tesis del Norte.

En este punto, como una conclusión básica, conviene recoger textualmente el demoledor planteamiento de Ha-Joon Chang (2002b), quien invita a rechazar los planteamientos de quienes arguyen que "lo que los países subdesarrollados necesitan son las 'buenas' políticas económicas y las instituciones que los países desarrollados mismos usaron para desarrollarse, tales como la liberalización del comercio y la inversión, y estrictas leyes de patentes.

La convicción en sus propias recomendaciones es absoluta, de manera tal que desde su punto de vista deben imponerse, a cualquier costo, sobre los países subdesarrollados mediante la fuerte presión externa bilateral o multilateral". 
Pues, según el propio Chang, "como es bien sabido, ha habido acalorados debates sobre si estas políticas e instituciones son adecuadas para los países subdesarrollados. La cosa curiosa es que incluso aquellos que son escépticos sobre lo adecuado raramente cuestionan si estas, las actuales, son las políticas y las instituciones que usaron los países desarrollados para volverse ricos. Sin embargo, el hecho histórico es que los países ricos no se desarrollaron sobre la base de las políticas e instituciones que ahora ellos recomiendan e incluso fuerzan para los países subdesarrollados".

\section{La necesidad de una visión estratégica, integradora y solidaria}

En estas condiciones, una respuesta adecuada exige buscar un régimen social de acumulación diferente al neoliberal, que no tenga como su eje y meta la inserción sumisa al mercado mundial. Esto conduce a diseñar una concepción estratégica de participación en el mercado mundial, como parte del proceso nacional-local de desarrollo, fortaleciendo una real integración regional.

El problema del desarrollo, entendido en su acepción contemporánea, tiene más que ver con la satisfacción de las necesidades humanas superiores que con la tasa de crecimiento del PIB, variable que no sería más que un medio para lograr los objetivos auténticamente humanos, esto es superar la pobreza y generar empleo, sin deterioro de la base natural en la que se desenvuelven los procesos productivos.

Para Ecuador, la noción de desarrollo sigue siendo esquiva. Es imperioso repensarlo desde su realidad, fundamentalmente en los aspectos vinculados con el desarrollo humano (educación, salud, atención básica) y productivo. 
Esta discusión se ha delegado a los organismos internacionales de crédito y a ciertas ONGs. Pero debe ser retomada a partir de los agentes involucrados y especialmente por parte del gobierno. El resultado esperado sería una visión multiparadigmática del desarrollo.

Este enfoque exige incorporar consideraciones económicas, así como también sociales y culturales. Debe ser una programación que guíe y ofrezca una serie de criterios tanto para el corto plazo como para los mediano y largo plazos. Para ponerlo en palabras de John Maynard Keynes, "no debería ser un asunto de romper raíces sino de entrenar lentamente a una planta para que crezca en una dirección diferente".

Por lo tanto, esta estrategia tendrá que ser suficientemente flexible para enfrentar las turbulencias del mercado mundial, las transformaciones que se deriven de la nueva revolución tecnológica, la complejidad creciente de fenómenos geopolíticos a nivel mundial y aun los complejos retos internos. En este empeño cabe aprovechar todas las capacidades disponibles, así como desarrollar ventajas comparativas dinámicas; en especial si se tiene presente la serie de limitaciones y dificultades que se derivan de la globalización capitalista que excluye sistemáticamente a la mayoría de la población mundial y que presenta un creciente antagonismo de los intereses del Norte y del Sur; antagonismo que se reproduce aun dentro de los países subdesarrollados. Todo en un ambiente donde afloran, de una manera abierta o solapada, las intromisiones imperiales y transnacionales.

Se requiere una visión integradora que reconozca los probables escenarios nacionales e internacionales de conflicto y demandas reales de seguridad, tanto como posibles espacios para potenciar el desarrollo. Urge una concepción de desarrollo que considere el momento histórico, la realidad política, económica y cultural de cada país, de la subregión 
y del mundo. Es cada vez más apremiante una reformulación del proceso de integración subregional y aún regional en marcha, para ampliar el campo de acción de sus aparatos productivos a partir de profundas reformas internas que potencien sus mercados domésticos y que permitan un accionar más inteligente en el concierto internacional.

Uno de los mayores escollos de la integración en América latina y el Caribe ha sido su conceptualización como un ejercicio económico, mayormente de tipo mercantil. Esta no solo debe servir para relanzar una estrategia exportadora de inspiración transnacional o para conseguir un simple acercamiento a la economía norteamericana en medio de un proceso de reordenamiento geopolítico complejo, cuyo resultado no está claro. La integración de cada una de las subregiones, como parte de un esfuerzo de integración latinoamericanista, tiene que apuntar a objetivos más amplios y profundos en un esfuerzo concertado por vencer al subdesarrollo y fortalecer la democracia. Ya es hora de pensar en la posibilidad de una supresión consensuada de las monedas nacionales y en un acercamiento real de nuestras políticas económicas, tal como sucede en Europa, como parte de una estrategia de cesión voluntaria de parte de nuestras soberanías nacionales a cambio de la construcción de una soberanía monetaria regional más amplia y eficiente. Hay que hacer posible el establecimiento y la vigencia de esquemas de acumulación y reproducción nacionales y regionales que se sustenten en una mayor participación ciudadana y que excluyan los regímenes autoritarios y represivos, que superen los dogmas y contradicciones neoliberales, para lo cual se tendrá que avanzar en las transformaciones económicas, sociales y políticas que cada sociedad requiere.

Por otro lado hay que salir de la trampa planteada por quienes creen que el problema para lograr el éxito de las políticas neoliberales es de "gobernabilidad", entendida esta 
como un esquema que facilite la consolidación del régimen social de acumulación neoliberal, sostenido en una mayor orientación hacia el mercado mundial -con una apertura y liberalización a ultranza- y en una menor injerencia de propuestas de inspiración nacional. Esta visión neoliberal, como sabemos de la experiencia de las últimas décadas, exige una creciente concentración de la riqueza con miras a promover el ahorro que financie nuevas inversiones, que ofrezca nuevos beneficios y garantías al capital externo, que acepte una mayor flexibilización laboral y un menor peso de la organización sindical y social en general. Además, provoca el fortalecimiento del gran empresariado privado (nacional y transnacional) en detrimento de la pequeña y mediana empresa, así como de los espacios empresariales comunitarios. Todo lo cual desemboca en un acrecentamiento del poder en manos de pocas personas: el hiperpresidencialismo, viable sobre bases de creciente autoritarismo y debilitamiento democrático.

La ingenuidad de las actuales estrategias del Banco Mundial, del BID y del FMI, así como también de Washington con el ALCA/TLC, radica precisamente en la creencia de que toda la economía puede, de la noche a la mañana, incorporarse activamente a la "nueva" división internacional del trabajo; cuando, en realidad, la globalización en marcha margina tendencialmente y en forma estructural a la mayoría de la población y a partes sustantivas del propio aparato productivo. El camino debe ser otro, aceptando el tránsito por un proceso paulatino, que requiere de un horizonte de preparación y bases de equidad, incluso para que los mercados "funcionen". Y con seguridad no solo habrá que marchar por un camino diferente, sino que la meta final deberá diferir de los imaginarios (imposibles) del neoliberalismo. 
Esta tarea implica un esfuerzo de largo aliento y de profundas transformaciones, cuyas connotaciones adquirirán una creciente urgencia en la medida que se profundicen las condiciones críticas desatadas internacional y nacionalmente, en el campo social, ecológico y hasta económico. Paulatinamente se perfila la necesidad de revisar el estilo de vida vigente a nivel de las elites y que sirve de marco orientador (si bien inalcanzable) para la mayoría de la población; una revisión que tendrá que procesar, sobre bases de real equidad, la reducción del tiempo de trabajo y su redistribución, así como la redefinición colectiva de las necesidades en función de satisfactores ajustados a las disponibilidades de la economía y la naturaleza. Este planteamiento, apenas esbozado en las líneas anteriores, resulta inviable dentro de la lógica del "libre comercio".

\section{A modo de conclusión}

La propuesta de anexión de las Américas -ALCA o TLC que en el fondo son lo mismo- no ofrece condiciones para integrar el hemisferio a partir de la equidad, la solidaridad y la sustentabilidad. No abre puertas para un desarrollo equilibrado y equitativo, menos aún democrático; recuérdese que hasta hace poco no se conocían informaciones sobre las negociaciones del ALCA, su contenido era secreto; algo similar ocurre hoy con los TLC, donde la confidencialidad en las negociaciones es la norma.

La esencia mercantilista y casi exclusivamente empresarial de la iniciativa de Washington -detrás de la cual asoman con claridad sus intereses militaristas y sus objetivos políticos imperiales- atenta incluso contra una verdadera integración hemisférica. Su doble discurso -apertura para sus productos en los mercados externos y protección frente a los bienes importados- ahoga cualquier opción equita- 
tiva en el campo del comercio. Las enormes diferencias de tamaño y de poder impiden una negociación equilibrada, más todavía con gobiernos entreguistas, mediocres, ingenuos y aun corruptos, que tampoco tiene la suficiente capacidad técnica para absolver los temas propuestos.

\section{Bibliografía}

- Acosta, Alberto y Falconí, Fander; "EI TLC, desempolvando el cuento del libre comercio", en Acosta, Alberto y Falconí, Fander; "TLC- Más que un tratado de libre comercio", ILDIS-FES y FLACSO, Quito, 2005.

- Acosta, Alberto; "El libre comercio o la vieja práctica de quitar la escalera", en Acosta, Alberto y Gudynas, Eduardo; "Libre comercio - Mitos y realidades", ILDIS, D3E, Abya-Yala, Quito, 2004.

- Acosta, Alberto; "El Área de Libre Comercio de las Américas y las inversiones extranjeras - Una propuesta de seguridad "social" para los capitales transnacionales", 2004, (mimeo).

- Acosta, Alberto. 2003. "Globalización o desglobalización, esa no es la cuestión". Memorias del Encuentro de Historia y Realidad Económica y Social de Ecuador y América Latina. Universidad de Cuenca. También disponible en www.globalizacion.org

- Acosta, Alberto. 2002. "Retos de la globalización para América Latina". Conferencia en la Jornada de Comercio Internacional: efectos en las economías del sur. Fundación "La Caixa", Barcelona, 26 de septiembre.

Disponible en http://www.lainsignia.org/2002/diciembre/dial_007.htm

- Bairoch, Paul. 1993. "Economics and World History: Myths and Paradoxes". Chicago.

- CEPAL. 2004. "La Inversión Extranjera en América Latina y el Caribe, Informe 2003", Santiago de Chile.

- Chang, Ha-Joon. 2002a. "Kicking Away the Ladder - Development Strategy in Historical Perspective". Londres, Anthem Press.

- Chang, Ha-Joon. 2002b. "De la historia del mundo desarrollado, la verdadera lección para los países subdesarrollados es: la libertad de elegir". Red Mexicana de Acción Frente al Libre Comercio (RMALC). http://www.rmalc.org.mx/documentos/historia_del_mundo_desarrollado.pdf

- de Sebastián, Luis. 1999. "El rey desnudo - Cuatro verdades sobre el mercado". Editorial Trota. Madrid.

- Diez Canseco, Javier. 2004. "El partido que el Perú se juega con el 
TLC”. Diario La República, Lima, abril. www.lainsignia.org/2004/abril/ibe_027.htm

- Ferrer, Aldo. 2002. Vivir con lo nuestro - Nosotros y la globalización. Buenos Aires: Fondo de Cultura Económica.

- Gratius, Susanne. 2002. "El proyecto del ALCA visto desde Europa". Santiago de Chile: Fundación Friedrich Ebert.

- Gudynas, Eduardo. 2003. "El déficit democrático de la OMC y las responsabilidades del Sur". Septiembre. http://www.lainsignia.org/2003/septiembre/econ_009.htm

- Keynes, John Maynard. 2003. Autosuficiencia Nacional Conferencia Finlay en el University College, Dublín, el 19 de Abril 1933, publicada en el Yale Review Vol 22 (4), 1933. Traducción al castellano del ILDISFES publicada por Ecuador Debate (CAAP), No 60, Quito,

- List, Friedrich. "Sistema nacional de economía política", Aguilar, Madrid (1955).

- Martí, José; La Revista llustrada, Nueva York (1891). Obras Completas, tomo 6, Editorial de Ciencias Sociales, La Habana.

- OXFAM. 2002. Cambiar las reglas - Comercio, globalización y lucha contra la pobreza. Intermon - OXFAM, Barcelona.

- Polanyi, Karl. 1944 (edición en castellano 1992). "La gran transformación - Los orígenes políticos y económicos de nuestro tiempo", Fondo de Cultura Económico. México.

- Polaski, Sandra. 2004. NAFTA's Promise and Reality. Carnegie Endowment for International Peace, Washington.

- Ponce, Javier, ed. y Alberto Acosta, coord. 2002. "Cartillas sobre el alca" (1 a 9). Quito: Instituto Latinoamericano de Investigaciones Sociales (ildis) / Fundación Friedrich Ebert (fes). Estos textos están disponibles, conjuntamente con otras cartillas de la FES en Santiago de Chile, en www.ildis.org

- Romero Cevallos, Marco; "ALCA y los Tratados de Libre Comercio (TLC): Significación histórica, alcances y desafíos para la integración andina", en Cárdenas, Miguel Eduardo (compilador); "El futuro de la integración andina", FESCOL y CEREC, Bogotá, 2004.

- Stiglitz, Joseph E. 2002, El malestar en la globalización, Taurus, Buenos Aires.

- Sunkel, Oswaldo. 1971. "Capitalismo transnacional y desintegración nacional en América Latina”, en El Trimestre Económico vol. 38, no. 150, abril-junio.

- Ugarteche, Óscar. 1990. "La hegemonía en crisis - Desafíos para la economía de América Latina”. Lima: Fundación Friedrich Ebert. 
